\title{
Optimal Buyer's Replenishment Policy in the Integrated Inventory Model for Imperfect Items
}

\author{
Lu Yueli, ${ }^{1}$ Mo Jiangtao, ${ }^{2}$ and Wei Yucheng ${ }^{1}$ \\ ${ }^{1}$ Hechi University, Hechi 546300, China \\ ${ }^{2}$ Guangxi University, Nanning 530004, China \\ Correspondence should be addressed to Lu Yueli; vivian28@126.com
}

Received 31 December 2015; Revised 14 June 2016; Accepted 9 August 2016

Academic Editor: Paolo Crippa

Copyright (c) 2016 Lu Yueli et al. This is an open access article distributed under the Creative Commons Attribution License, which permits unrestricted use, distribution, and reproduction in any medium, provided the original work is properly cited.

\begin{abstract}
In the classical economic order quantity (EOQ) models, a common unrealistic assumption is that all the items received are of good quality. However, in realistic environment, a received shipment usually contains a fraction of imperfect quality items. These imperfect items may be scrapped, reworked at a cost, or salvaged at a discounted price. While the percentage of imperfect items is random, the optimal ordering cycle is rarely considered in current literatures. This paper revisits the model (Maddah and Jaber, 2008) and extends it by assuming that the ordering cycle is determined by the demand rate, delivery quantity per shipment, and the mathematical expectation of the defective rate. The possibility of stockout or residue in the end of a cycle will be considered, and the loss of stockout and the salvage of the residue are counted into the cost. Besides, we consider consolidating the shipments of imperfect items over multiple deliveries. Thus, an integrated vendor-buyer inventory model for imperfect quality items with equal-size shipment policy is established to derive the optimal ordering cycle, ordering quantity, and number of deliveries. The computational method of the optimal delivery quantity per shipment and number of deliveries is given through theoretical results. Finally, sensitivity of main parameters is analyzed through simulation experiments and shown by some figures.
\end{abstract}

\section{Introduction}

Management's view on inventory has been changed significantly over the several decades. Previously, managers perceived inventory as an asset. Since the life cycles of product are becoming ever shorter, a wide variety of problems concealed in the excessive inventories are prominent, for instance, the expensive inventory storage costs. Plant managers make their effort to reduce inventories in all categories, from raw materials, purchased parts, and working process, to the finished goods. The economic order quantity (EOQ) model was first introduced by Harris [1] in the last century to settle two fundamental questions: "when should an order be placed?" and "how much should it be ordered?". This great work assisted companies in reducing their total inventory costs and provided managers with guidelines to choose the appropriate replenishment policy. Since then, a large amount of extensions to the EOQ model have been studied in the past decades. An unrealistic assumption in Harris's model [1] is that all the items received are of good quality. In reality, the goods received always contain some items with imperfect quality, due to many unpredictable factors, such as the imperfect production or transportation. The imperfect items may be scrapped, reworked at a cost, or salvaged at a discounted price, which causes the additional costs. Therefore, the effects of imperfect quality must be considered when seeking policies for optimizing order quantity and the other related inventory control parameters, such as the ordering cycle and shipment times. Porteus [2] and Rosenblatt and Lee [3] began to investigate the imperfect product process problem firstly. Along their line of research, scholars have made abundant achievements.

It is well known that Salameh and Jaber [4] first proposed an EOQ model in which a random ratio of the products in an order is defective. The buyer conducts a $100 \%$ inspection to split the qualified products from the defective ones, after which the defective products are sold at a discounted price as a single batch at the completion of the inspection. Their 
model has been extended from various aspects. Goyal and Cárdenas-Barrón [5] amended a tiny error in the initial model and presented a simpler approach that approximately determined the economic production quantity. Rezaei [6], Eroglu and Ozdemir [7], and Wee et al. [8] extended the original model to account for backorders. Papachristos and Konstantaras [9] discussed the assumption in original model to avoid shortage and extended the original model on the assumption that defective products were accumulated until the end of the planning horizon and then withdrawn. Maddah and Jaber [10] rectified a flaw in original model related to the approach of assessing the expected profit. Chang and Ho [11] revisited the work of Wee et al. [8] and applied the renewal-reward theorem in the model and acquired a new expected net profit. Chung and Huang [12] first incorporated imperfect quality with trade credit, and then Jaggi et al. [13] extended the model to the situation that shortages were allowed and fully backlogged. Based on the learning curve theory, Konstantaras et al. [14] investigated an allowable shortage EOQ model for the cases of infinite and finite planning horizons when the fraction of defective items can be reduced by learning; Alamri et al. [15] established a general EOQ model for imperfect quality items by assuming that demand, screening, and deterioration rates were all arbitrary functions of time. Moussawi-Haidar et al. [16] developed two modified EOQ-type models for deteriorating items when the proportion of defective items follows a known distribution. They first assumed that no shortages are allowed, that is, the inventory level is just enough to cover the demand during the screening period, and then relaxed the assumption and allowed for backordering. Finally, they analyzed the impact of deterioration on the instantaneous replenishment model and presented the managerial implications. Unlike the abovementioned studies in which the inspection process is conducted by buyer, Rezaei and Salimi [17] studied economic order quantity and purchasing price for items contained defects when inspection process transfers from buyer to vendor. Yassine et al. [18] considered an augmented EPQ model in which the inspection is conducted by supplier. They first developed a base model where the defective products are repaired once at the end of each production circle. Then, they extended the base model to two scenarios, disaggregating the shipments of defective products in a single run and aggregating the shipments of defective products over multiple runs, and derived closed-form expressions for the economic production quantity. Chang [19] corrected some typos that appeared in Yassine et al. [18] soon afterwards. Noting that inspector of product quality control might make some inspection errors during the separation of imperfect and perfect items, TaheriTolgari et al. [20] considered two types of inspection errors under inflationary conditions. J.-T. Hsu and L.-F. Hsu [21, 22] established an EOQ model and two EPQ models for imperfect quality items, respectively, by integrating with inspection errors, shortage backordering, and sales returns. Based on the unreliable supply, Moussawi-Haidar et al. [23] developed an instantaneous replenishment model for imperfect items under a sampling policy, that is, using an acceptance sampling inspection instead of $100 \%$ screening, whose results indicated that the optimal profit obtained was significantly higher. Jaber et al. [24] presented two models by assuming that imperfect items were repaired or replaced by good ones from a local supplier at a higher cost when the shipment was provided by a distant supplier, signifying a practical implication in today's globalised supply chains. Sarkar et al. [25] developed three different economic production quantity models for three different distribution density functions with rework process and planned backorders for a single stage manufacturing system. Al-Salamah [26] presented an EPQ model based on a scenario where the production process and inspection are both imperfect. They sought the optimal lot size for a manufacturer while batches are subjected to destructive or nondestructive acceptance sampling process before batches can be sent out to the market. In order to investigate the effect of yield variability and the stochastic behavior of the defective rate, L.-F. Hsu and J.-T. Hsu [27] developed different EPQ models with shortages backordered for cases of constant and random defective rate under three moments of withdrawing the defective items: (a) as they are detected, (b) at the end of each production period, or (c) at the end of each production cycle. They derived out the optimal production lot size and backorder quantity and showed that the effects of both yield variability and withdrawal timing are not critical factors, which implicated that managements could make decisions by taking advantage of the mean defective rate when the probability density function of the defective rate is difficult to obtain. For a detailed review and discussion of the extensions of the original model proposed by Salameh and Jaber [4], see Khan et al. [28].

In the abovementioned models, the ordering cycle can be roughly divided into two kinds. One kind is that the cycle time $T$ is relative to the demand rate $D$, the order quantity $y$, and the defective rate $p$ which is a random variable; that is, $T=(1-p) y / D$. Thus, $T$ is a random variable too. Most of the models belong to this kind, such as Salameh and Jaber [4], Goyal and Cárdenas-Barrón [5], Eroglu and Ozdemir [7], Wee et al. [8], Papachristos and Konstantaras [9], Chung and Huang [12], and Yassine et al. [18]. However, none of the abovementioned models derived the optimal cycle time. The other kind is that the cycle time is a deterministic variable; that is, $T=(1-E(p)) y / D$, where $E(p)$ is the mathematical expectation of $p$. The optimal cycle time is obtained when the optimal ordering quantity is found. The models proposed by Rezaei [6] and L.-F. Hsu and J.-T. Hsu [27] are examples. In this kind of the model, the defective rate $p$ is a random variable and the cycle time $T$, the demand rate $D$, and order quantity $y$ are deterministic. Based on such an assumption, it is obvious that two possibilities may happen at the end of cycle: stockout or residue. This will result in the loss of stockout or the salvage of residue. However, there is no related discussion about the case of residue at the end of cycle in the abovementioned models.

In this paper, an integrated supplier-buyer inventory model for imperfect quality items with equal-size shipment policy is established to derive the optimal ordering cycle, order quantity, and number of deliveries. This study extends the model proposed by Maddah and Jaber [10] in three ways. First, it considers the optimal ordering cycle by assuming that the cycle time is determined by the demand rate $D$, delivery 
quantity per shipment $y$, and the mathematical expectation of the defective rate $p$, just like that of Rezaei [6]. Secondly, stockout and residue in the end of a cycle are considered due to the randomness of the defective rate, and the loss of stockout and the salvage of the residue are counted into the cost. This is quite different from that of Rezaei [6], which only considered the possibility of shortage. Thirdly, this model incorporates with equal-size shipment policy; that is, the supplier delivers a lot to the buyer in $n$ shipments of equal size. A $100 \%$ screening process is implemented when the buyer received each shipment.

The residual of this paper is organized as follows. Section 2 states the notations and assumptions of the model. Sections 3 and 4 are for the mathematical modeling and the theoretical results to determine the optimal ordering quantity and number of deliveries, respectively. Section 5 provides numerical examples and analysis of results. Section 6 summarizes and concludes the paper.

\section{Notations and Assumptions}

\subsection{Notations}

$T$ : ordering cycle (decision variable),

Q: order quantity per cycle (decision variable),

$y$ : delivery quantity per shipment (decision variable),

$n$ : number of deliveries (decision variable),

$D$ : demand rate per year,

$K$ : ordering cost per order,

$x$ : screening rate,

$d$ : screening cost per unit,

$h$ : holding cost per unit per year,

$c$ : purchasing price per unit item,

$p$ : percentage of defective items in one lot, a random variable,

$\mu$ : expectation of random variable $p$,

$s$ : selling price of qualified items per unit,

$v$ : residual value of defective items per unit,

$c_{s}$ : residual value of qualified items per unit,

$c_{l}$ : shortage cost per unit,

$E[x]$ : mathematical expectation of $x$,

$[x]^{+}:[x]^{+}=\max \{x, 0\}$,

$[x]$ : the largest integer that is less then or equal to $x$.

\subsection{Assumptions}

(a) Time horizon is infinite.

(b) Demand rate, $D$, is known and constant.

(c) Lead time is omitted, and the items are delivered instantaneously. (d) The items provided by supplier contain a percentage $p$ of defective items, where $p$ is a random variable over interval $[a, b]$ with the probability density function $f(p)$ and the mathematical expectation $\mu$, where $0<$ $a, b<1$.

(e) The buyer's ordering cycle is $T=(1-\mu) Q / D$ and places an order of quantity $Q$ in each cycle. The supplier delivers them in $n$ shipments of equal sizes $y$ with the time interval $t=(1-\mu) y / D$. Obviously, $Q=n y$ and $T=n t$.

(f) When a shipment is received, the buyer begins a $100 \%$ inspection process at rate $x$ immediately. To avoid stockout during the screening time, it is assumed that $1-D / x \geq b$; this condition insures that the amount of perfect quality items in a shipment is at least equal to the demand during the screening time.

(g) The defective items are stored and consolidated at a lot at the end of the final inspection period in $n$th time interval $t$, that is, $[(n-1) t, n t]$. The buyer can gain residual value of the defective items at a discounted price of $v$ per unit.

(h) At the end of time interval $[(i-1) t, i t]$, that is, at the moment it, the residual qualified items are sold at a discounted price of $c_{s}$ per unit if residue happens, or the shortages lead to a penalty cost of $c_{l}$ per unit, $i=$ $1,2, \ldots, n$.

\section{Model Formulation}

Based on the assumptions, the buyer places an order of quantity $Q$ at the beginning of each cycle. Then, the supplier delivers the items in $n$ shipments of equal size $y$ at time $(i-1) t, i=1,2, \ldots, n$. The buyer inspects the received items immediately. The defective items are stored till the last screening process finishes, that is, at the time of $(n-1) t+$ $y / x$, and then consolidated in one lot. The buyer's aim is to determine the optimal delivery quantity per shipment $y^{*}$ and the optimal number of deliveries $n^{*}$ such that the expected profit per unit time is maximized.

The total revenue of the buyer includes the revenue of qualified and the salvage value of defective items and residual qualified items, which are separately calculated as follows:

(a) The revenue of qualified items is $n s \min \{(1 \quad$ p) $y, D t\}=\operatorname{sn} y \min \{1-p, 1-\mu\}$.

(b) The salvage value of defective items is $v p n y$.

(c) The salvage value of residual qualified items is $n c_{s}[(1-$ p) $y-D t]^{+}=n y c_{s}[\mu-p]^{+}$.

Thus, the total revenue of the buyer in a cycle is

$$
\begin{aligned}
& \operatorname{TR}(y, n) \\
& \quad=n y\left\{s \min \{1-p, 1-\mu\}+v p+c_{s}[\mu-p]^{+}\right\} .
\end{aligned}
$$

The total cost of the buyer includes purchasing cost, screening cost, shortage cost, and holding cost. They are separately calculated as follows:

(d) The purchasing cost is $K+c n y$.

(e) The inspection cost is $d n y$. 


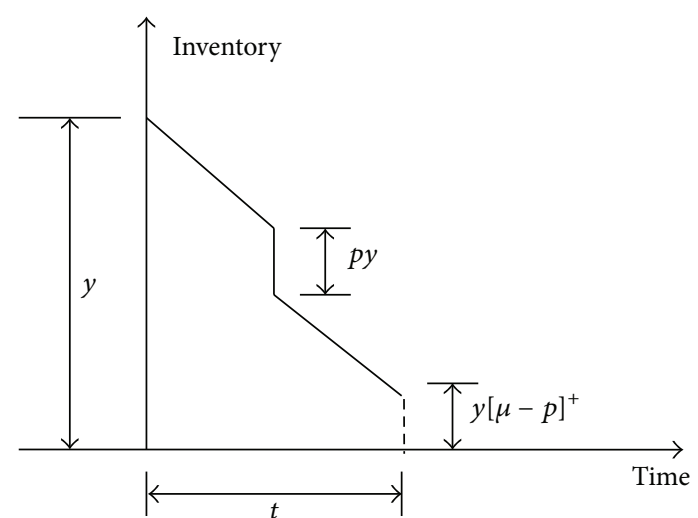

Figure 1: Behavior of inventory level of qualified items with no shortage in time interval $t$.

(f) The shortage cost is $n c_{l}[D t-(1-p) y]^{+}=n y c_{l}[p-\mu]^{+}$.

(g) The holding cost of qualified items depends on the inventory level at the end of the time interval $t$.

When there is no shortage at the end of the time interval $t$, the behavior of inventory level of qualified items is illustrated in Figure 1. The quantity of storage of qualified items is

$$
\begin{aligned}
n \frac{1}{2} & \left\{(1-p) y+y[\mu-p]^{+}\right\} t \\
& =\frac{1}{2 D} n y^{2}\left\{(1-p)+[\mu-p]^{+}\right\}(1-\mu) .
\end{aligned}
$$

When shortage happens at the end of the time interval $t$, the behavior of inventory level of qualified items is illustrated in Figure 2. The quantity of storage of qualified items is

$$
\begin{array}{r}
n \frac{1}{2}(y-p y)\left\{t-\frac{1}{D}[D t-(1-p) y]^{+}\right\} \\
=\frac{1}{2 D} n y^{2}(1-p)\left\{1-\mu-[p-\mu]^{+}\right\} .
\end{array}
$$

Since $[\mu-p]^{+}>0$ if and only if $[p-\mu]^{+}=0$, the quantity of storage of qualified items in a cycle can have a unified representation as follows:

$$
\frac{1}{2 D} n y^{2}\left\{(1-p)+[\mu-p]^{+}\right\}\left\{1-\mu-[p-\mu]^{+}\right\} .
$$

Then, the holding cost of qualified items in a cycle is

$$
\frac{1}{2 D} h n y^{2}\left\{(1-p)+[\mu-p]^{+}\right\}\left\{1-\mu-[p-\mu]^{+}\right\} .
$$

(h) The behavior of inventory level of defective items in a cycle is illustrated in Figure 3.

For $i=1,2, \ldots, n-1$, the defective items in the items that arrived at time $(i-1) t$ will be stored until being at time $(n-$ 1) $t+y / x$ and then consolidated in one lot. We can derive the holding cost of defective items during different time interval: from time $(i-1) t$ to time $(n-1) t$ is $(n-i) h p y t$, from time $(n-1) t$ to time $(n-1) t+y / x$ is $h p y^{2} / x$, and at time $(i-1) t$

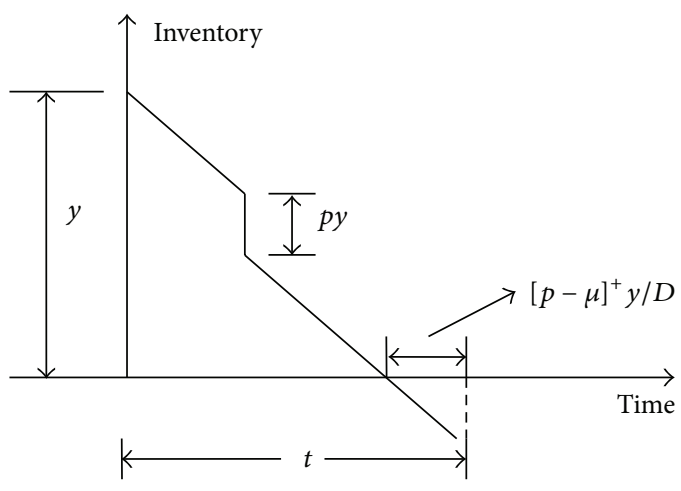

FIGURE 2: Behavior of inventory level of qualified items with shortage in time interval $t$.

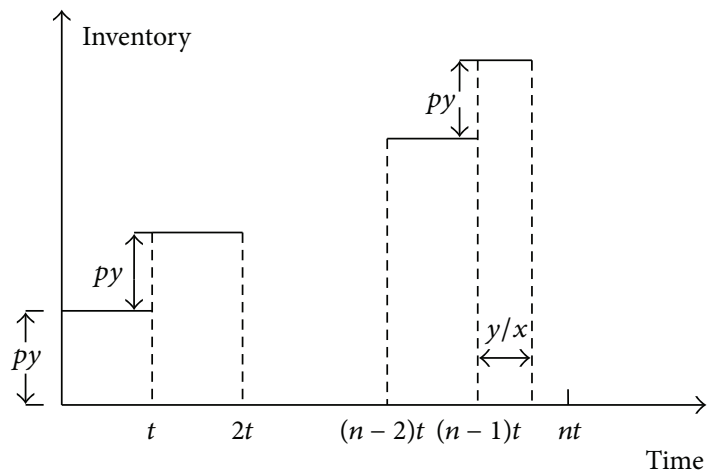

FIGURE 3: Behavior of inventory level of defective items in a cycle.

is $(n-i) h p y t+h p y^{2} / x$. Then, the holding cost of defective items in a cycle is

$$
\begin{aligned}
& \sum_{i=1}^{n-1}\left[(n-i) h p y t+\frac{h p y^{2}}{x}\right] \\
& \quad=h p n y^{2}\left[\frac{1}{2 D}(n-1)(1-\mu)+\frac{1}{x}\right] .
\end{aligned}
$$

Therefore, the total cost of the buyer in a cycle is

$$
\begin{aligned}
& \mathrm{TC}(y, n)=K+n y\left\{c+d+c_{l}[p-\mu]^{+}+\frac{1}{x} h p y\right\} \\
& +\frac{1}{2 D} \\
& \cdot h n y^{2}\left\{\left\{(1-p)+[\mu-p]^{+}\right\}\left\{1-\mu-[p-\mu]^{+}\right\}\right. \\
& +(n-1)(1-\mu) p\} .
\end{aligned}
$$

From what has been discussed above, the total profit of the buyer in a cycle is

$$
\begin{aligned}
\operatorname{TP} & (y, n)=\operatorname{TR}(y, n)-\operatorname{TC}(y, n) \\
& =n y\left\{s \min \{1-p, 1-\mu\}+p\left(v-\frac{1}{x} h y\right)\right. \\
& \left.+c_{s}[\mu-p]^{+}-c-d-c_{l}[p-\mu]^{+}\right\}-\frac{1}{2 D}
\end{aligned}
$$




$$
\begin{aligned}
& \cdot h n y^{2}\left\{\left\{(1-p)+[\mu-p]^{+}\right\}\left\{1-\mu-[p-\mu]^{+}\right\}\right. \\
& +(n-1)(1-\mu) p\}-K .
\end{aligned}
$$

The expected total profit of buyer in a cycle is given by

$$
\begin{gathered}
\operatorname{ETP}(y, n)=n y\{s E[\min \{1-p, 1-\mu\}]-c-d \\
\left.+\mu\left(v-\frac{1}{x} h y\right)+c_{s} E[\mu-p]^{+}-c_{l} E[p-\mu]^{+}\right\} \\
\quad-\frac{1}{2 D} h n y^{2}\left\{E \left[\left\{(1-p)+[\mu-p]^{+}\right\}\right.\right. \\
\left.\left.\cdot\left\{1-\mu-[p-\mu]^{+}\right\}\right]+(n-1)(1-\mu) \mu\right\}-K .
\end{gathered}
$$

The expected total profit per unit time of the buyer in a cycle is given by

$$
\begin{aligned}
& \operatorname{ETPU}(y, n)=\frac{\operatorname{ETP}(y, n)}{T} \\
& =\frac{D}{1-\mu}\{s E[\min \{1-p, 1-\mu\}]-c-d+\mu v \\
& \left.+c_{s} E[\mu-p]^{+}-c_{l} E[p-\mu]^{+}\right\}-\frac{D K}{(1-\mu) n y} \\
& \quad-\frac{h y}{2(1-\mu)}\left\{(1-\mu)[1+(n-2) \mu]+\frac{2 D \mu}{x}\right. \\
& \left.+(1-\mu) E[\mu-p]^{+}-E\left[(1-p)(p-\mu)^{+}\right]\right\} .
\end{aligned}
$$

The mathematical model of inventory problem considered in this paper is

$$
\begin{array}{ll}
\max & \operatorname{ETPU}(y, n) \\
\text { s.t. } & y \geq 0, \\
& n \geq 0 .
\end{array}
$$

\section{Theoretical Results}

We first look for the optimal value of $y$ that maximizes $\operatorname{ETPU}(y, n)$ for a given $n$.

Taking the first-order partial derivative of $\operatorname{ETPU}(y, n)$ with respect to $y$, we obtain

$$
\frac{\partial \operatorname{ETPU}(y, n)}{\partial y}=\frac{1}{2(1-\mu)}\left[\frac{2 D \kappa(n)}{y^{2}}-h \gamma(n)\right],
$$

where

$$
\begin{aligned}
\kappa(n)= & \frac{K}{n}, \\
\gamma(n)= & (1-\mu)[1+(n-2) \mu]+2 D \frac{\mu}{x} \\
& +(1-\mu) E[\mu-p]^{+} \\
& -E\left[(1-p)(p-\mu)^{+}\right] .
\end{aligned}
$$

Lemma 1. For any integer $n>0, \gamma(n)>0$.

Proof. Since $a \leq p \leq b, 0<a<b<1$, if $a \leq p \leq \mu$, then

$$
\begin{aligned}
& (1-\mu) \int_{a}^{\mu}(\mu-p) f(p) d p \\
& \quad-\int_{\mu}^{b}(1-p)(p-\mu) f(p) d p \\
& \quad=(1-\mu) \int_{a}^{\mu}(\mu-p) f(p) d p-0 \geq 0,
\end{aligned}
$$
lemma.

and if $\mu \leq p \leq b$, then $1-\mu \geq 1-p$ and

$$
\begin{aligned}
& (1-\mu) \int_{a}^{\mu}(\mu-p) f(p) d p \\
& -\int_{\mu}^{b}(1-p)(p-\mu) f(p) d p \\
& \geq(1-\mu) \int_{a}^{\mu}(\mu-p) f(p) d p \\
& -\int_{\mu}^{b}(1-\mu)(p-\mu) f(p) d p \\
& =(1-\mu) \int_{a}^{b}(\mu-p) f(p) d p=0 .
\end{aligned}
$$

On the other hand, if $n=1$, then $(1-\mu)[1+(n-2) \mu]=$ $(1-\mu)^{2} \geq 0$; if $n \geq 2,(1-\mu)[1+(n-2) \mu] \geq 0$ is obvious.

From the discussion above, $\gamma(n)>0$ holds for any positive integer $n$.

Then, from the result above, we can obtain the following

Lemma 2. For any given $n$, there exists the unique value of $y$ (denoted by $\tilde{y}(n))$ which maximizes $\operatorname{ETPU}(y, n)$ on $y \in$ $[0,+\infty)$.

Proof. The first-order necessary condition with respect to $y$ for $\operatorname{ETPU}(y, n)$ to be maximized is

$$
\frac{\partial \operatorname{ETPU}(y, n)}{\partial y}=0 .
$$

From Lemma 1, we obtain the value of $y$ (denoted by $\widetilde{y}(n))$ as

$$
\tilde{y}(n)=\sqrt{\frac{2 D \kappa(n)}{h \gamma(n)}} .
$$

Since

$$
\frac{\partial^{2} \operatorname{ETPU}(y, n)}{\partial y^{2}}=-\frac{2 D}{1-\mu}\left(K+\frac{K_{s}}{n}\right) \frac{1}{y^{3}} \leq 0,
$$

thus $\operatorname{ETPU}(y, n)$ is a concave function of $y>0$. Therefore, $\tilde{y}(n)$ is the unique value of $y$ which maximizes $\operatorname{ETPU}(y, n)$ on $y \in[0,+\infty)$. 
Substituting $y$ with $\tilde{y}(n)$ into $\operatorname{ETPU}(y, n)$ and denoting $\operatorname{ETPU}_{1}(n)=\operatorname{ETPU}(\tilde{y}(n), n)$, we have

$$
\operatorname{ETPU}_{1}(n)=\frac{\left\{D\left\{s E[\min \{1-p, 1-\mu\}]+v \mu+c_{s} E[\mu-p]^{+}-c_{l} E[p-\mu]^{+}-c-d\right\}-\sqrt{2 D h \kappa(n) \gamma(n)}\right\}}{(1-\mu)}
$$

It is easy to see that maximizing $\operatorname{ETPU}_{1}(n)$ is equivalent to minimizing

$$
g(n)=\kappa(n) \gamma(n)
$$

on $[1,+\infty)$. For convenience, let

$$
\begin{aligned}
\Delta= & (1-\mu)(1-2 \mu)+\frac{2 D \mu}{x}+(1-\mu) E[\mu-p]^{+} \\
& -E\left[(1-p)(p-\mu)^{+}\right] .
\end{aligned}
$$

Lemma 3. There exists unique $\tilde{n}$ such that $\operatorname{ETPU}_{1}(n)$ obtains the maximum value on $[1,+\infty)$, and

$$
\widetilde{n}= \begin{cases}1, & \Delta \leq 0 ; \\ \sqrt{\frac{\Delta}{\mu(1-\mu)},} & \Delta>0 .\end{cases}
$$

Proof. The first-order and second-order derivative of $g(n)$ are given by

$$
\begin{aligned}
& g^{\prime}(n)=-\frac{K}{n^{2}} \Delta+K \mu(1-\mu), \\
& g^{\prime \prime}(n)=\frac{2 K}{n^{3}} \Delta .
\end{aligned}
$$

If $\Delta \leq 0$, then $g^{\prime}(n)>0$ and $g^{\prime \prime}(n) \leq 0$; that is, $g(n)$ is increasing concave function of $n$. Thus, $g(n)$ achieves its minimum value on $[1,+\infty)$ at $\widetilde{n}=1$. This implies that $\operatorname{ETPU}_{1}(n)$ achieves its maximum value on $[1,+\infty)$ at $\widetilde{n}=1$.

If $\Delta>0$, since $0<\mu<1$, there exists the unique value of $n$ on $[1,+\infty)\left(\right.$ denoted by $\left.n_{0}\right)$ such that $g^{\prime}(n)=0$ and

$$
n_{0}=\sqrt{\frac{\Delta}{\mu(1-\mu)}}
$$

Furthermore, $g^{\prime}(n)<0$ if $n \leq n_{0}$ and $g^{\prime}(n)>0$ if $n>n_{0}$; that is, $g(n)$ decreases on $\left[1, n_{0}\right)$ and increases on $\left[n_{0},+\infty\right)$. Thus, $g(n)$ achieves its minimum value on $[1,+\infty)$ at $\widetilde{n}=$ $n_{0}$. Accordingly, $\operatorname{ETPU}_{1}(n)$ achieves its maximum value on $[1,+\infty)$ at $\widetilde{n}=n_{0}$.

Since the optimal number of deliveries $n^{*}$ is an integer, from the discussion above, we have

$$
n^{*}=\arg \max \left\{\operatorname{ETPU}_{1}([\widetilde{n}]), \operatorname{ETPU}_{1}([\widetilde{n}]+1)\right\},
$$

where $[x]$ is the largest integer that is less than or equal to $x$. Hence, we obtain the optimal delivery quantity per shipment $y^{*}=\widetilde{y}\left(n^{*}\right)$, the optimal order quantity per cycle $Q^{*}=n^{*} y^{*}$, and the optimal ordering cycle $T^{*}=(1-\mu) Q^{*} / D$.

If the number of deliveries $n^{*}=1$, we get the optimal delivery quantity per shipment $y^{*}=\sqrt{2 D K / h}\left(1 /\left((1-\mu)^{2}+\right.\right.$ $\left.\left.2 D \mu / x+(1-\mu) E[\mu-p]^{+}-E\left[(1-p)(p-\mu)^{+}\right]\right)\right)^{1 / 2}$ and the optimal order quantity $Q^{*}=y^{*}$. Furthermore, we can derive that $Q^{*}=y^{M J} \sqrt{1+\Delta_{1}} \geq y^{M J}$, where $y^{\mathrm{MJ}}=\sqrt{2 D K / h} / \sqrt{E\left[(1-p)^{2}\right]+2 \mu D / x}$ is the optimal order quantity of Maddah and Jaber's model [10], and $\Delta_{1}=(a-$ $b)^{2} /\left[8(a-b)^{2}+24(1-a)(1-b)+48 \mu D / x\right]$ is obtained under the assumption that the fraction of defective items $p$ is uniformly distributed on $(a, b)$; that is, $p \sim U(a, b), 0 \leq a<b<1$.

\section{Numerical Examples}

In order to verify the results of our model, we develop a series of simulation experiments based on the example from Maddah and Jaber's model [10].

Example 1. Given $D=50000$ units/year, $x=175200$ units/ year, $d=\$ 0.5 /$ unit, $K=\$ 100 /$ cycle, $h=\$ 5 /$ unit/year, $c=$ $\$ 25 /$ unit, $s=\$ 50 /$ unit, $v=\$ 10 /$ unit, $c_{s}=\$ 16 /$ unit, $c_{l}=$ $\$ 5 /$ unit, and $K_{s}=\$ 50 /$ delivery, $p \sim U(a, b), 0 \leq a<b<1$, $a=0$. When $b$ takes different values, the relevant results are shown in Table 1 and Figure 4.

From Table 1, we know that when $b$ and $\mu$ increase, the optimal number of deliveries, order quantity, ordering cycle, and expected profit per unit time all decrease, but the optimal delivery quantity per shipment increases. When the defective rate increases, the number of defective items is larger; in order to satisfy the demand in each time interval, the number of deliveries should be decreased as a result of more products needing to be delivered per shipment. In addition, more defective items are accumulated in each time interval, which will bring more holding costs and reduce the expected profit per unit time. For fear of more storage, we should reduce the order quantity and shorten the ordering cycle to dispose the defective items in time. In particular, the variation of number of deliveries and order quantity is more outstanding when the defective rate is small, which demonstrates that the influence of the defective items on inventory strategy cannot be ignored.

Example 2. Given that $b=0.04$ and the values of other parameters are the same as in Example 1, when $D$ takes different values, the values of $n^{*}, y^{*}$, and $\operatorname{ETPU}\left(y^{*}\right)$ are shown in Table 2 and Figure 5.

From Table 2, we know that when the demand rate increases, the optimal number of deliveries is unchanged and 
TABLE 1: The effects of $b$ and $\mu$ on $n^{*}, y^{*}, Q^{*}, T^{*}$, and $\operatorname{ETPU}\left(y^{*}\right)$.

\begin{tabular}{lcccccc}
\hline$b$ & $\mu$ & $n^{*}$ & $y^{*}$ & $Q^{*}$ & $T^{*}$ & $\mathrm{ETPU}\left(y^{*}\right)$ \\
\hline 0.005 & 0.0025 & 20 & 309.52 & 6190.39 & 0.12 & 1220216.38 \\
0.010 & 0.0050 & 15 & 354.24 & 5313.61 & 0.11 & 1216764.36 \\
0.020 & 0.0100 & 10 & 431.35 & 4313.46 & 0.09 & 1209905.73 \\
0.040 & 0.0200 & 7 & 512.10 & 3584.71 & 0.07 & 1196388.14 \\
0.060 & 0.0300 & 6 & 549.57 & 3297.39 & 0.06 & 1182827.11 \\
0.080 & 0.0400 & 5 & 603.49 & 3017.45 & 0.06 & 1168943.69 \\
0.100 & 0.0500 & 5 & 597.22 & 2986.13 & 0.06 & 1155027.56 \\
0.200 & 0.1000 & 3 & 797.30 & 2391.88 & 0.04 & 1080076.89 \\
0.300 & 0.1500 & 3 & 790.50 & 2371.48 & 0.04 & 997244.98 \\
0.400 & 0.2000 & 2 & 1042.11 & 2084.21 & 0.03 & 903377.53 \\
0.500 & 0.2500 & 2 & 1052.27 & 2104.55 & 0.03 & 797831.19 \\
\hline
\end{tabular}

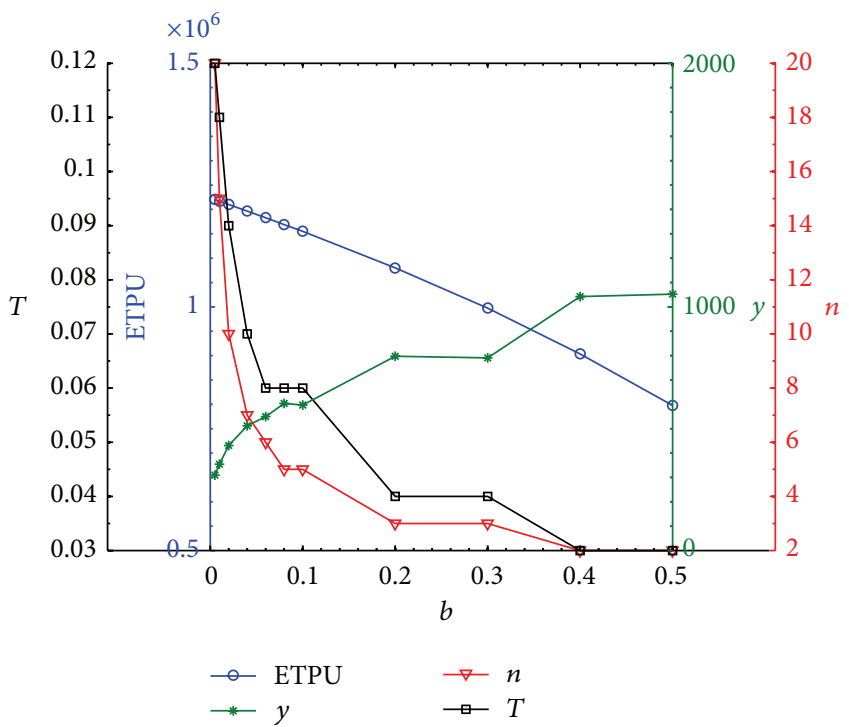

FIGURE 4: The optimal replenishment policy for different defective rate.

the optimal order quantity and expected profit per unit time all increase, which is obvious. However, the optimal ordering cycle increases for the reason of the numerous defective items needing to be disposed in time.

Example 3. Given that $b=0.04$ and the values of other parameters are the same as in Example 1, when $K$ takes different values, the values of $n^{*}, y^{*}$, and $\operatorname{ETPU}\left(y^{*}\right)$ are shown in Table 3 and Figure 6.

From Table 3, we know that when the ordering cost increases, the optimal number of deliveries is unchanged and the optimal order quantity and ordering cycle all increase, but expected profit per unit time decreases. When the ordering cost is high, in order to save cost, retailer considers ordering more products in an ordering cycle and extending the cycle, which leads to the decreases of the optimal expected profit per unit time for more accumulated defective items and the longer storage time.
TABle 2: The effects of $D$ on $n^{*}, y^{*}, Q^{*}, T^{*}$, and $\operatorname{ETPU}\left(y^{*}\right)$.

\begin{tabular}{lccccc}
\hline$D$ & $n^{*}$ & $y^{*}$ & $Q^{*}$ & $T^{*}$ & $\operatorname{ETPU}\left(y^{*}\right)$ \\
\hline 50000 & 7 & 512.10 & 3584.70 & 0.070 & 1196388.13 \\
60000 & 7 & 560.39 & 3922.74 & 0.064 & 1435960.11 \\
70000 & 7 & 604.66 & 4232.62 & 0.059 & 1675553.42 \\
80000 & 7 & 645.73 & 4520.15 & 0.055 & 1915163.56 \\
90000 & 8 & 634.37 & 5074.97 & 0.055 & 2155003.24 \\
\hline
\end{tabular}

TABLE 3: The effects of $K$ on $n^{*}, y^{*}, Q^{*}, T^{*}$, and $\operatorname{ETPU}\left(y^{*}\right)$.

\begin{tabular}{lccccc}
\hline$K$ & $n^{*}$ & $y^{*}$ & $Q^{*}$ & $T^{*}$ & $\operatorname{ETPU}\left(y^{*}\right)$ \\
\hline 100 & 7 & 512.10 & 3584.70 & 0.070 & 1196388.13 \\
150 & 7 & 627.19 & 4390.35 & 0.086 & 1195748.38 \\
200 & 7 & 724.22 & 5069.54 & 0.099 & 1195209.05 \\
250 & 7 & 809.70 & 5667.92 & 0.111 & 1194733.89 \\
300 & 7 & 886.98 & 6208.89 & 0.122 & 1194304.31 \\
\hline
\end{tabular}

TABLE 4: The effects of $h$ on $n^{*}, y^{*}, Q^{*}, T^{*}$, and $\operatorname{ETPU}\left(y^{*}\right)$.

\begin{tabular}{cccccc}
\hline$h$ & $n^{*}$ & $y^{*}$ & $Q^{*}$ & $T^{*}$ & $\operatorname{ETPU}\left(y^{*}\right)$ \\
\hline 5 & 7 & 512.10 & 3584.70 & 0.070 & 1196388.13 \\
6 & 7 & 467.48 & 3272.37 & 0.064 & 1196116.44 \\
7 & 7 & 432.80 & 3029.63 & 0.059 & 1195866.60 \\
8 & 7 & 404.85 & 2833.96 & 0.056 & 1195634.05 \\
9 & 7 & 381.69 & 2671.88 & 0.052 & 1195415.64 \\
\hline
\end{tabular}

TABLE 5: The effects of $x$ on $n^{*}, y^{*}, Q^{*}, T^{*}$, and ETPU $\left(y^{*}\right)$.

\begin{tabular}{lccccc}
\hline$x$ & $n^{*}$ & $y^{*}$ & $Q^{*}$ & $T^{*}$ & $\mathrm{ETPU}\left(y^{*}\right)$ \\
\hline 175200 & 2 & 1042.10 & 2084.21 & 0.033 & 903377.53 \\
185200 & 2 & 1045.61 & 2091.22 & 0.033 & 903397.64 \\
195200 & 2 & 1048.78 & 2097.57 & 0.034 & 903415.74 \\
205200 & 2 & 1051.68 & 2103.36 & 0.034 & 903432.13 \\
215200 & 2 & 1054.32 & 2108.64 & 0.034 & 903447.03 \\
\hline
\end{tabular}

Example 4. Given that $b=0.04$ and the values of other parameters are the same as in Example 1, when $h$ takes different values, the values of $n^{*}, y^{*}$, and $\operatorname{ETPU}\left(y^{*}\right)$ are shown in Table 4 and Figure 7.

From Table 4, we know that when the holding cost increases, the optimal number of deliveries is unchanged, but the optimal order quantity, ordering cycle, and expected profit per unit time all decrease. In order to avoid more storage when the holding cost per unit per year increases, we should reduce the delivery quantity per shipment, shorten the ordering cycle, and dispose the defective items in time.

Example 5. Given that $b=0.4$ and the values of other parameters are the same as in Example 1, when $x$ takes different values, the values of $n^{*}, y^{*}$, and $\operatorname{ETPU}\left(y^{*}\right)$ are shown in Table 5 and Figure 8.

Table 5 shows that when the screening rate increases, the optimal number of deliveries is unvaried and the optimal order quantity, ordering cycle, and expected profit per unit 


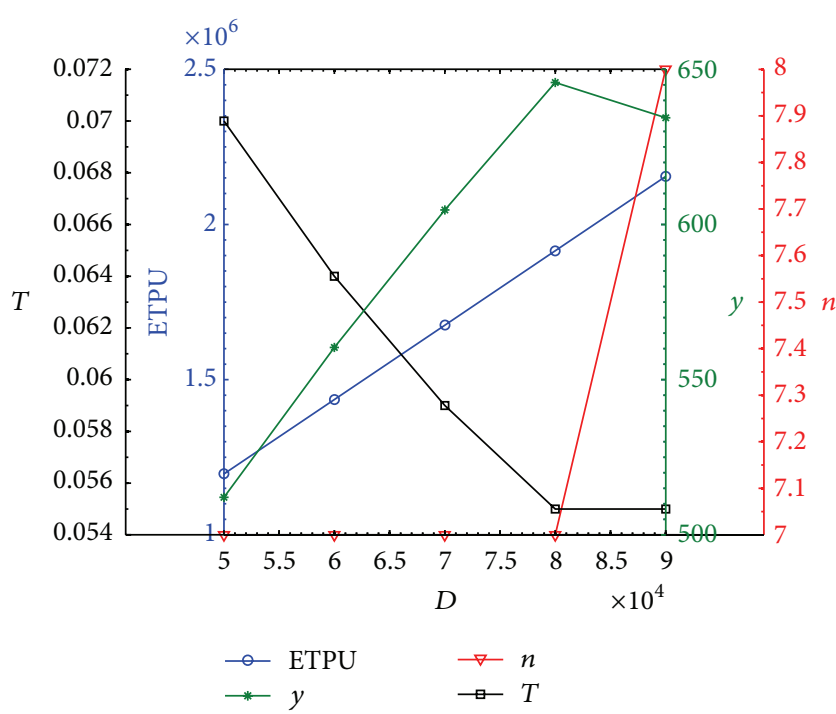

FIgURE 5: The optimal replenishment policy for different demand rate $D$.

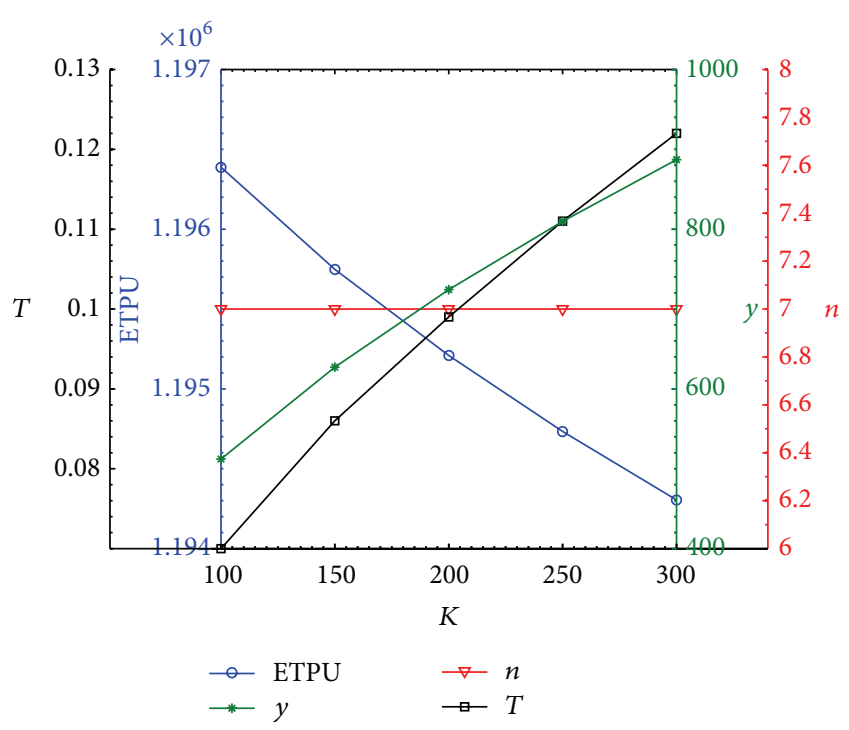

FIGURE 6: The optimal replenishment policy for different ordering cost $K$.

time all increase, but the amplitude of variation is tiny. On the one hand, the defective items are kept in storage after the inspection and continuously produce the holding costs until the end of inspection period in the time interval $n$. For this reason, when the screening rate varies, the storage time of defective items is only influenced by the inspection period in the time interval $n$. On the other hand, for the inspection period gets shorter when the screening rate increases, even though the defective rate is high, the quantity of defective items increases, but the storage time is shorter; therefore, the holding costs barely change. Consequently, the variation of the optimal expected profit and order quantity is small.

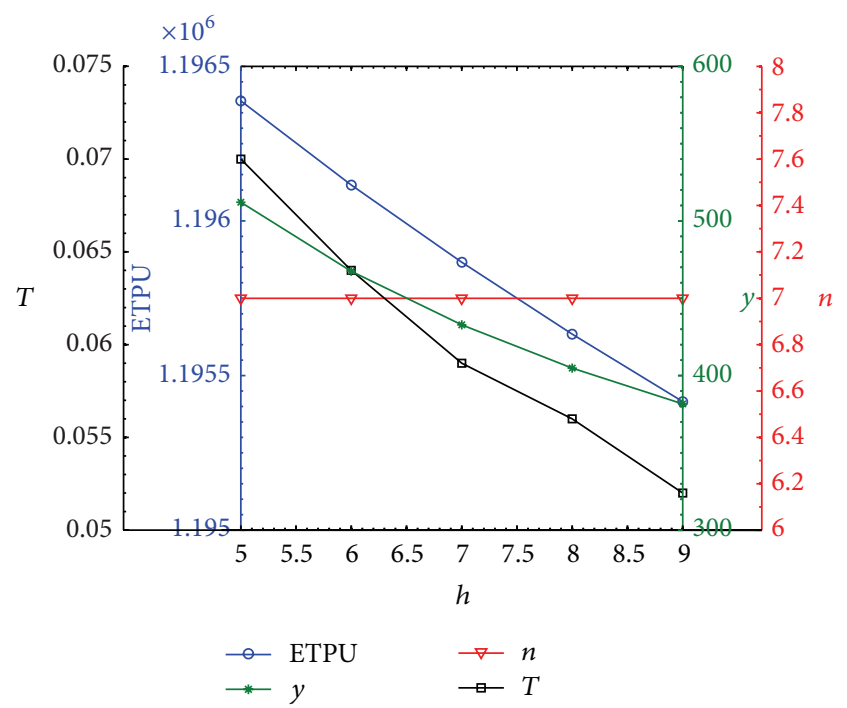

FIgURE 7: The optimal replenishment policy for different holding cost $h$.

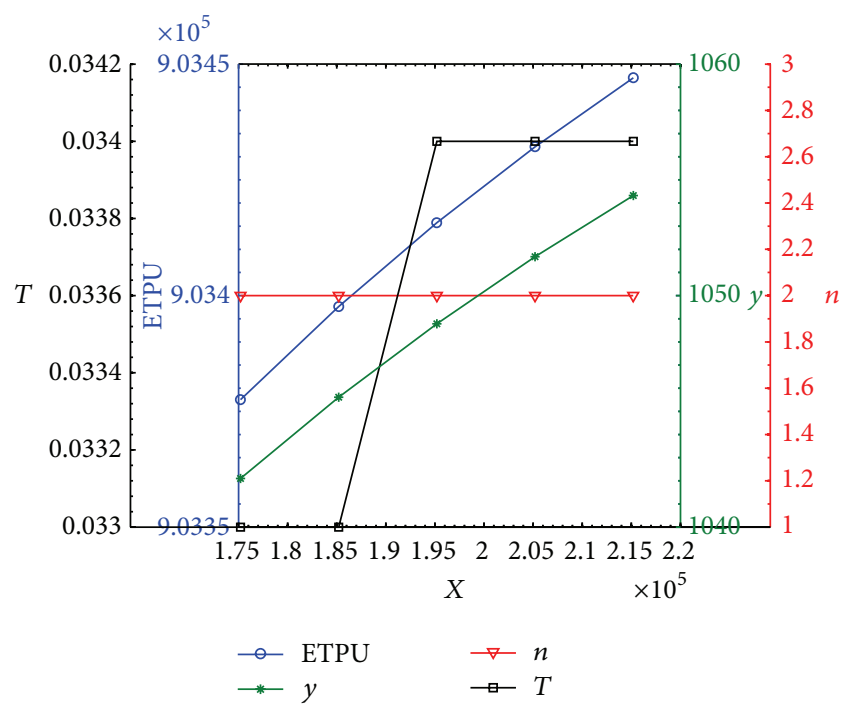

FIGURE 8: The optimal replenishment policy for different screening rate $x$.

\section{Conclusions}

Most of the researchers only presented the optimal order quantity when developing the models for imperfect items with random defective rate. But few researchers discussed the optimal cycle time. When the cycle time is determined by the demand rate, delivery quantity per shipment, and the mathematical expectation of the defective rate, stockout and residue will happen in the end of a cycle due to the randomness of the defective rate, but there is no related discussion about the case of residue in current literatures. This paper investigates the problem of replenishment policy that multiple deliveries are used and defective items are consolidated. We first establish an inventory model optimizing the retailer's expected profit per unit time, then give the computational method 
of the optimal delivery quantity per shipment and number of deliveries, and finally present numerical examples and sensitivity analysis of the major parameters. Compared with Maddah and Jaber's model [10] (called MJ model), this paper has the following two improvements: (i) The optimal ordering cycle is not given in MJ model but presented in this paper. (ii) The possibilities of residue or shortage is not considered in MJ model, but the economic impact of salvage or stockout on the inventory system at the end of the cycle is considered in this paper; that is, the loss of stockout and the salvage of the residue are counted into the cost. Thus, our paper provides a significant contribution by settling the question of "when should an order be placed?" in inventory management and does better than any other replenishment policy for imperfect items with random defective rate ignoring the possibility of residual. The managers of various industry departments will be benefited from the results as the defective rate is random variable which is quite general in the industry.

Future extensions of the proposed model are possible in several ways. First, our work could be improved by considering the effect of trade credit or inflation on the economic order quantity. Also, we may consider a modified inventory model by integrating deterioration and imperfect quality for items based on the same assumption. Another interesting extension is to consider an acceptance sampling inspection instead of $100 \%$ screening, where only a small portion of an order is screened, which may bring improvement in the profit. Furthermore, we can consider the effect of inspection errors during the separation of defective and perfect items.

\section{Competing Interests}

The authors declare that there is no conflict of interests regarding the publication of this paper.

\section{Acknowledgments}

This work is supported by National Natural Science Foundation of China (71261002) and Research Science Project of Hechi University (XJ2015KQ003).

\section{References}

[1] F. W. Harris, "How many parts to make at once," Factory, The Magazine of Management, vol. 10, no. 2, pp. 135-136, 1913, Reprinted in Operations Research vol. 38, pp. 947-950, 1990.

[2] E. L. Porteus, "Optimal lot sizing, process quality improvement, and setup cost reduction," Operations Research, vol. 34, no. 1, pp. 137-144, 1986.

[3] M. J. Rosenblatt and H. L. Lee, "Economic production cycles with imperfect production processes," IIE Transactions, vol. 18, no. 1, pp. 48-55, 1986.

[4] M. K. Salameh and M. Y. Jaber, "Economic production quantity model for items with imperfect quality," International Journal of Production Economics, vol. 64, no. 1-3, pp. 59-64, 2000.

[5] S. K. Goyal and L. E. Cárdenas-Barrón, "Note on: Economic production quantity model for items with imperfect qualitya practical approach," International Journal of Production Economics, vol. 77, no. 1, pp. 85-87, 2002.
[6] J. Rezaei, "Economic order quantity model with backorder for imperfect quality items," in Proceedings of the IEEE International Engineering Management Conference (IEMC '05), vol. 2, pp. 466-470, September 2005.

[7] A. Eroglu and G. Ozdemir, "An economic order quantity model with defective items and shortages," International Journal of Production Economics, vol. 106, no. 2, pp. 544-549, 2007.

[8] H. M. Wee, J. Yu, and M. C. Chen, "Optimal inventory model for items with imperfect quality and shortage backordering," Omega, vol. 35, no. 1, pp. 7-11, 2007.

[9] S. Papachristos and I. Konstantaras, "Economic ordering quantity models for items with imperfect quality," International Journal of Production Economics, vol. 100, no. 1, pp. 148-154, 2006.

[10] B. Maddah and M. Y. Jaber, "Economic order quantity for items with imperfect quality: revisited," International Journal of Production Economics, vol. 112, no. 2, pp. 808-815, 2008.

[11] H.-C. Chang and C.-H. Ho, "Exact closed-form solutions for 'optimal inventory model for items with imperfect quality and shortage backordering"' Omega, vol. 38, no. 3-4, pp. 233-237, 2010.

[12] K.-J. Chung and Y.-F. Huang, "Retailer's optimal cycle times in the EOQ model with imperfect quality and a permissible credit period," Quality \& Quantity, vol. 40, no. 1, pp. 59-77, 2006.

[13] C. K. Jaggi, S. K. Goel, and M. Mittal, "Credit financing in economic ordering policies for defective items with allowable shortages," Applied Mathematics and Computation, vol. 219, no. 10, pp. 5268-5282, 2013.

[14] I. Konstantaras, K. Skouri, and M. Y. Jaber, "Inventory models for imperfect quality items with shortages and learning in inspection," Applied Mathematical Modelling, vol. 36, no. 11, pp. 5334-5343, 2012.

[15] A. A. Alamri, I. Harris, and A. A. Syntetos, "Efficient inventory control for imperfect quality items," European Journal of Operational Research, vol. 254, no. 1, pp. 92-104, 2016.

[16] L. Moussawi-Haidar, M. Salameh, and W. Nasr, "Effect of deterioration on the instantaneous replenishment model with imperfect quality items," Applied Mathematical Modelling, vol. 38, no. 24, pp. 5956-5966, 2014.

[17] J. Rezaei and N. Salimi, "Economic order quantity and purchasing price for items with imperfect quality when inspection shifts from buyer to supplier," International Journal of Production Economics, vol. 137, no. 1, pp. 11-18, 2012.

[18] A. Yassine, B. Maddah, and M. Salameh, "Disaggregation and consolidation of imperfect quality shipments in an extended EPQ model," International Journal of Production Economics, vol. 135, no. 1, pp. 345-352, 2012.

[19] H.-C. Chang, "An economic production quantity model with consolidating shipments of imperfect quality items: a note," International Journal of Production Economics, vol. 144, no. 2, pp. 507-509, 2013.

[20] J. Taheri-Tolgari, A. Mirzazadeh, and F. Jolai, "An inventory model for imperfect items under inflationary conditions with considering inspection errors," Computers \& Mathematics with Applications, vol. 63, no. 6, pp. 1007-1019, 2012.

[21] J.-T. Hsu and L.-F. Hsu, "An EOQ model with imperfect quality items, inspection errors, shortage backordering, and sales returns," International Journal of Production Economics, vol. 143, no. 1, pp. 162-170, 2013.

[22] J.-T. Hsu and L.-F. Hsu, "Two EPQ models with imperfect production processes, inspection errors, planned backorders, and sales returns," Computers \& Industrial Engineering, vol. 64, no. 1, pp. 389-402, 2013. 
[23] L. Moussawi-Haidar, M. Salameh, and W. Nasr, "An instantaneous replenishment model under the effect of a sampling policy for defective items," Applied Mathematical Modelling, vol. 37, no. 3, pp. 719-727, 2013.

[24] M. Y. Jaber, S. Zanoni, and L. E. Zavanella, "Economic order quantity models for imperfect items with buy and repair options," International Journal of Production Economics, vol. 155, pp. 126-131, 2014.

[25] B. Sarkar, L. E. Cárdenas-Barrón, M. Sarkar, and M. L. Singgih, "An economic production quantity model with random defective rate, rework process and backorders for a single stage production system," Journal of Manufacturing Systems, vol. 33, no. 3, pp. 423-435, 2014.

[26] M. Al-Salamah, "Economic production quantity in batch manufacturing with imperfect quality, imperfect inspection, and destructive and non-destructive acceptance sampling in a twotier market," Computers \& Industrial Engineering, vol. 93, pp. 275-285, 2016.

[27] L.-F. Hsu and J.-T. Hsu, "Economic production quantity (EPQ) models under an imperfect production process with shortages backordered," International Journal of Systems Science, vol. 47, no. 4, pp. 852-867, 2016.

[28] M. Khan, M. Y. Jaber, A. L. Guiffrida, and S. Zolfaghari, "A review of the extensions of a modified EOQ model for imperfect quality items," International Journal of Production Economics, vol. 132, no. 1, pp. 1-12, 2011. 


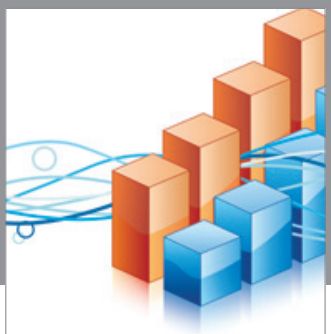

Advances in

Operations Research

vatem alat4

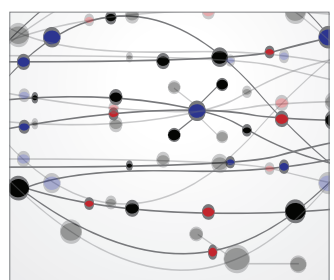

\section{The Scientific} World Journal
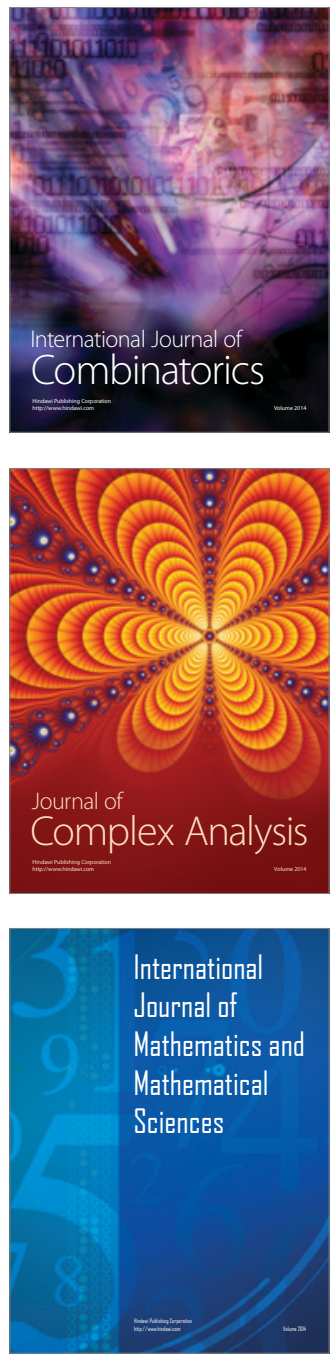
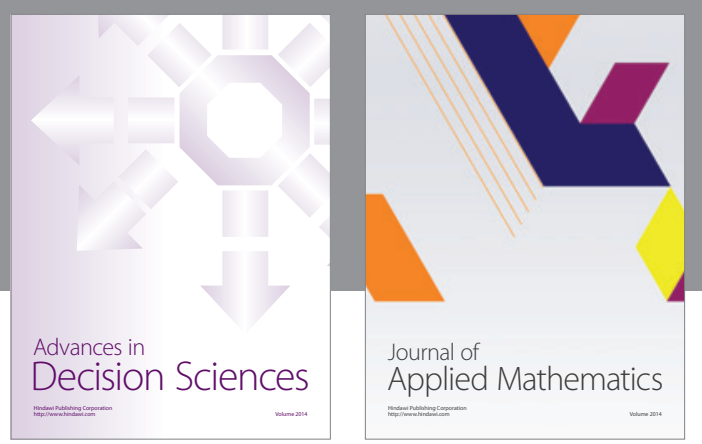

Algebra

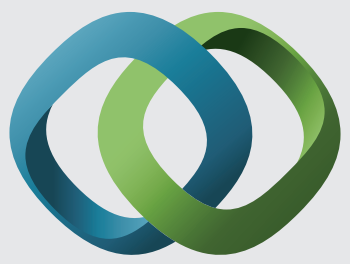

\section{Hindawi}

Submit your manuscripts at

http://www.hindawi.com
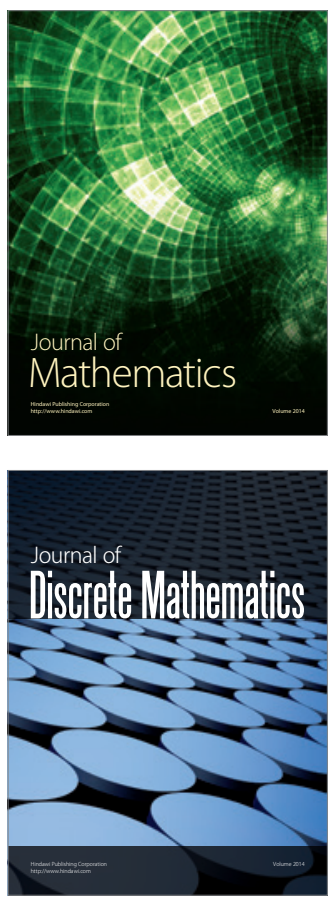

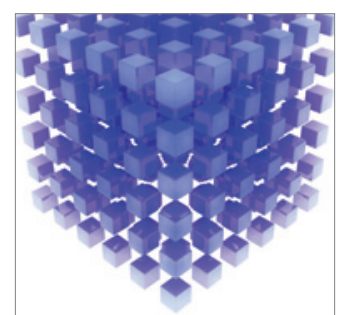

Mathematical Problems in Engineering
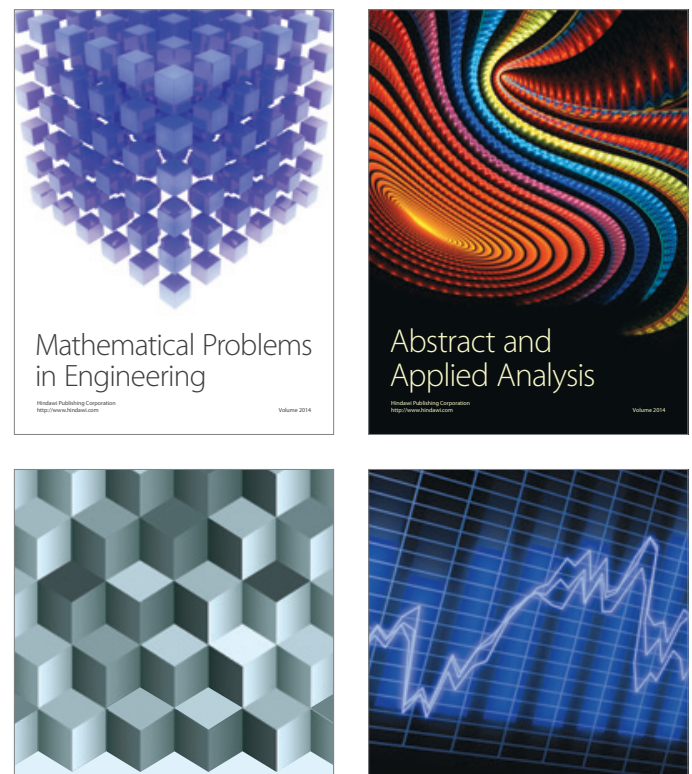

Journal of

Function Spaces

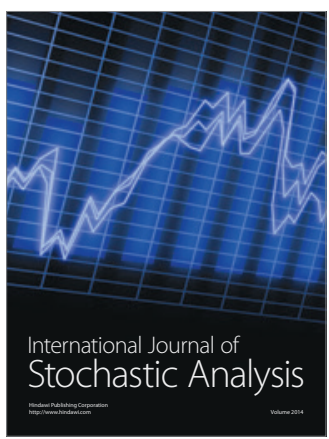

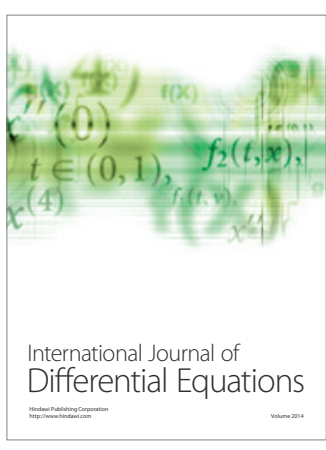
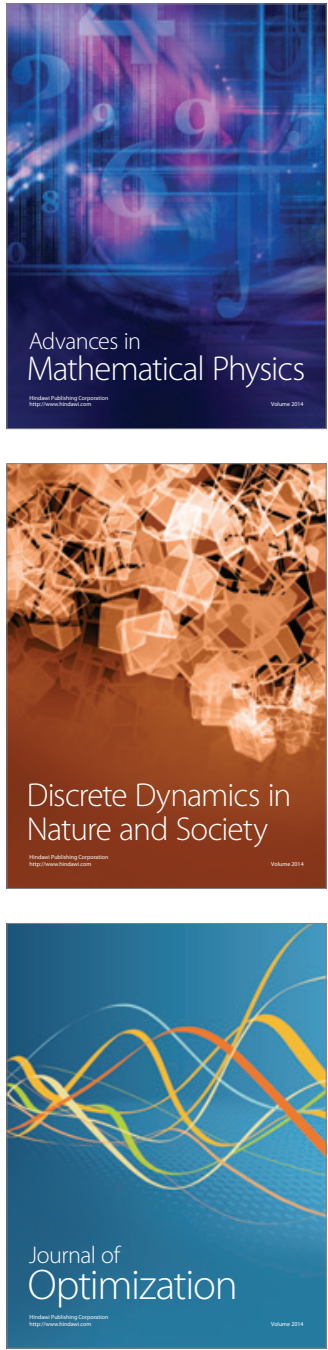